\title{
Effect of ethnicity, season and age on axial and peripheral bone mineral density: results from the Vitamin D, Food Intake, Nutrition and Exposure to Sunlight in Southern England (D-FINES) Study
}

\author{
Faisal Hanjra ${ }^{1}$, Puikwan Lee ${ }^{2}$, Jaana Nurmi-Lawton ${ }^{2}$, Warren Lee ${ }^{2}$, Richard Gray ${ }^{3}$, Pippa Cardew ${ }^{4}$, \\ Annette Duckworth ${ }^{4}$, Jacqueline Berry ${ }^{5}$, Sanjeev Patel ${ }^{6}$ and Susan Lanham-New ${ }^{2}$ \\ ${ }^{1}$ Queen Mary's School of Medicine \& Dentistry, London, UK, ${ }^{2}$ University of Surrey, Guildford, UK, \\ ${ }^{3}$ Mount Alvernia Hospital, Guildford, UK, ${ }^{4}$ Nuffield Hospital, Guildford, UK, ${ }^{5}$ University of Manchester, Manchester, UK \\ and ${ }^{6}$ St Helier Hospital, Carshalton, UK
}

Bone mineral density (BMD) is the measure of the absolute amount of bone. It correlates well with the general health of the bone, its strength and its ability to bear weight ${ }^{(1)}$. The measurement of BMD allows for the prediction of fracture risk ${ }^{(2)}$. Little is known about the effect of ethnicity on diet, physical activity and BMD. Thus, the principal aim of the present study was to investigate the effect of season and ethnicity on axial and peripheral BMD in UK pre- and post-menopausal women. The specific objective was to determine whether there was a seasonal variation in lumbar spine and femoral neck (FN) BMD in Caucasian and Asian women living in the UK.

The BMD data were collected from the D-FINES study, which included seasonal data on 242 Caucasian and seventy-two Asian women aged 19-70 years (mean age (years) 50.4 (SD 14.3) and 49.7 (SD 11.6 respectively) over a period of 12 months. Women were randomly recruited through general practitioners or through Asian community networks in Woking, Kingston and Thornton Health. BMD was measured in autumn 2006 (September-December) and spring 2007 (March-June) by dual X-ray absorptiometry (QDR; Hologic Inc., Bedford, MA, USA). Other measurements undertaken included data on dietary intake and fasted blood samples for assessment of vitamin D status.

\begin{tabular}{|c|c|c|c|c|c|c|c|c|}
\hline \multirow[t]{3}{*}{ Ethnicity ... } & \multicolumn{4}{|c|}{ Caucasian } & \multicolumn{4}{|c|}{ Asian } \\
\hline & \multicolumn{2}{|c|}{ Autumn } & \multicolumn{2}{|c|}{ Spring } & \multicolumn{2}{|c|}{ Autumn } & \multicolumn{2}{|c|}{ Spring } \\
\hline & Mean & SD & Mean & SD & Mean & SD & Mean & SD \\
\hline FN BMD $\left(\mathrm{g} / \mathrm{cm}^{2}\right)$ & $0.792^{\mathrm{a}}$ & 0.109 & $0.787^{\mathrm{b}}$ & 0.111 & 0.805 & 0.104 & 0.806 & 0.113 \\
\hline FT BMD $\left(\mathrm{g} / \mathrm{cm}^{2}\right)$ & $0.807^{\mathrm{a}}$ & 0.122 & $0.714^{\mathrm{b}}$ & 0.100 & 0.709 & 0.123 & 0.713 & 0.162 \\
\hline FW BMD $\left(\mathrm{g} / \mathrm{cm}^{2}\right)$ & 0.672 & 0.152 & 0.676 & 0.153 & 0.675 & 0.133 & 0.683 & 0.139 \\
\hline $\mathrm{F}$ total $\mathrm{T}$ score & -0.346 & 0.984 & -0.398 & 0.958 & -0.227 & 0.839 & -0.255 & 0.875 \\
\hline
\end{tabular}

The Table shows that in Caucasian women autumn BMD was significantly higher when compared with spring BMD at the hip BMD sites, which remained significant after adjustment for dietary $\mathrm{Ca}$ and vitamin $\mathrm{D}$ intake. However, no seasonal differences were found in the Asian women. The novel seasonal data in ethnic groups may possibly be explained by variations in vitamin D (25-hydroxyvitamin D) status $^{(3)}$ in Caucasian women but not Asian women and this finding requires further investigation. Analysis is now underway to explore the association between bone health, anthropometrics and vitamin D metabolism (including 25-hydroxyvitamin D status, parathyroid hormone and serum $\mathrm{Ca}$ ) in the D-FINES dataset.

This work was funded by the Food Standard Agency (N05064). The views expressed are the authors' own. The D-FINES Study is indebted to the following individuals and organisations for their help with subject recruitment: Mrs R Hanjra and Mrs Razia Killedar, Islamic Resource Centre, Kingston; Mrs Shanaz Bano, Woking Khidmat Group; Mrs Raefia Mahoon, Woking Asian Women's Association; Mrs Rohini Mahendran, Thornton Health Asian Association; Mrs Freda Smithers, College Road Surgery, Woking, the late Mr John Pheasant, Thornton Heath Medical Centre.

1. Loveridge N \& Lanham-New SA (2008) British Nutrition Foundation Taskforce on Nutritional Aspects of Ageing. London: Blackwell Publishing (In the Press).

2. World Health Organization (1994) Assessment of Fracture Risk and its Application to Screening and Postmenopausal Osteoporosis. Technical Report Series no. 843. Geneva: WHO.

3. Hypponen E \& Power C (2007) Am J Clin Nutr 85, 860-888. 